\title{
黒鎑炉ゼーマン原子吸光法による電解金属クロム中の 微量アンチモンの定量
}

\author{
北條 孝, 南雲 信光 ${ }^{\circledR *}$
}

(1983 年 8 月 26 日受理)

\begin{abstract}
黑鉛炉ゼーマン原子吸光法による電解金属クロム中の微量フンチモンの定量法を検討した。まず標集 液を用いて微量アンチモン $(0.1 \mu \mathrm{g} / \mathrm{ml})$ を高感度で測定するための基礎条件について検討し，検出限 界 $0.002 \mu \mathrm{g} / \mathrm{ml}(20 \mu \mathrm{l}$ 注入), 乙の付近の濃度での変動係数 $2.5 \%(n=10)$ を得た. 各種酸（塩酸, 硝酸, 硫酸, 過塩素酸及びリン酸) 及びクロムの共存は, 塩酸を除いて, 高濃度になると吸光度を低下 させた。クロムが大量に共存した場合, 乾燥及び灰化の過程で試料の突沸, 原子化の過程でバックグラ ウンドの吸収過大の現象が現れ測定を困難とするので標準液より得られた基礎条件を変更しクロム共 存時の分析方法を確立した．本法を電解金属クロムを塩酸と硝酸で分解して得られる検液（クロム濃度 $5000 \mu \mathrm{g} / \mathrm{ml}$ ) に適用し，フンチモンを，分離などの前処理を行うことなく直接定量することができた. 定量下限は $0.4 \mathrm{ppm}$ であった。
\end{abstract}

\section{1 緒 言}

電解金属クロム（以下金属クロムと略称）は，スーパ ーアロイに多く使用されているが，アンチモンなどの低 融点微量不純物は, 数 $\mathrm{ppm}$ 程度存在してもスーパーア ロイの強度に有害な影響を与えると言われている1)2).

このような観点から, 金属クロム中のこれら元素の高 感度かつ迅速な分析が求められている.

微量アンチモンの分析は, 共存元素から分離した後に 定量する溶媒抽出法3) 5) や水素化物法6) -9) で広く行われ ているが，煩雑で長時間を要する.

近時, 共存成分を分離することなく直接高感度で分析 する方法として，バックグラウンド補正機構を持つ黒鉛 炬原子吸光法が注目されているが, 金属クロム中の微量 アンチモンの定量に関する報告は少なく10) 12)，検出限 界付近の 低濃度領域に打ける 測定条件, 共存成分の影 響などについての系統的な検討はほとんど行われていな い.

著者らは, 金属クロム中の数 $\mathrm{ppm}$ 以下の微量アンチ モンを共存成分からの分離などの前処理を行うことなく 迅速に定量する方法として, ゼーマン効果を利用した黒 鉛炉原子吸光法の適用を検討しその有用性を確認したの で報告する.

* 東洋曹達工業 (株) 東京研究所 : 252 神奈川県綾瀬 市早川 2743-1

\section{2 試薬及び装置}

\section{1 試 薬}

アンチモン標準液 (A) : 市販の原子吸光分析用アン チモン標準液 $(1000 \mu \mathrm{g} / \mathrm{ml}, 3 \mathrm{~N}$ 塩酸酸性溶液) を原液 とし，使用の都度，原液を塩酸 $(1+9)$ でうすめて 1.2 $\mathrm{N}$ 塩酸酸性溶液として用いた。

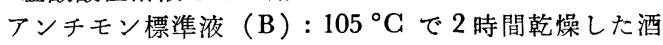
石酸アンチモニルカリウム（特級試薬） $2.6684 \mathrm{~g}$ を水に 溶解し 11 とし, 原液 $(1000 \mu \mathrm{g} / \mathrm{ml})$ とした. 使用の都 度この原液を水でうすめて用いた。

塩酸, 硝酸, 硫酸, 過塩素酸 : 原子吸光分析用試薬を 用いた.

その他の試薬：特級品を用いた。

水：イオン交換水を用いた。

\section{2 装}

日立製作所製 170-70 形ゼーマン原子吸光光度計，同 社製アンチモン中空陰極ランプ, 同社製 056 形 2 ペン レコーダー及びェッペンドルフ社製マイクロピペット $\{(5 〜 20) \mu l\}$ を用いた。

\section{3 基礎条件の検討}

\section{1 操 作}

アンチモン標準液（A）（アンチモン濃度 $0.1 \mu \mathrm{g} / \mathrm{ml}$ 以下) $20 \mu \mathrm{l}$ をマイクロピペットで黒鉛管に注入し，ア ルゴンを $31 / \mathrm{min}$ の流量で流しながら段階的に温度を上 げて, 乾燥, 灰化, 原子化を行い吸光度を測定した。 
原子吸光法の測定条件は，Table 1（1）に示すとお りとした。

Table 1 Instrumental operating conditions

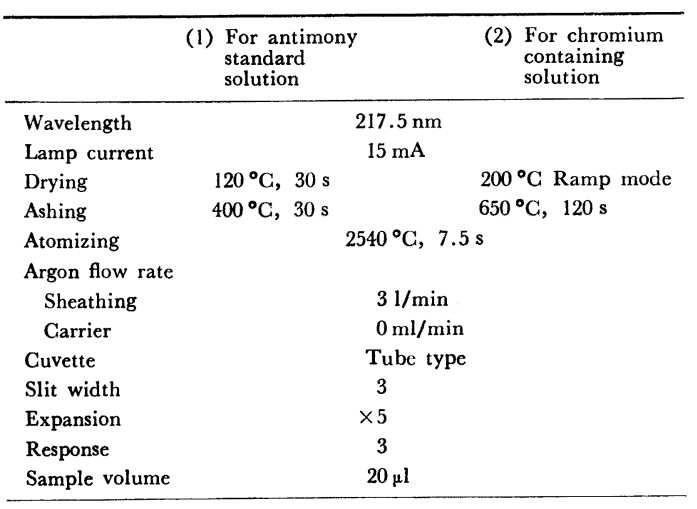

\section{2 結果と考察}

3.2.1 ランプ電流の影響 ランプ電流を $(7.5 \sim 20)$ $\mathrm{mA}$ の範囲で変化させ, 吸光度を測定し, ランプ電流の 影響を検討した。

ランプ電流は吸光度にほとんど影響を与えなかった が，高電流側でベースラインのノイズ幅は小さくなり， 検出限界濃度を小さくする傾向を示した. ランプの寿命 を考慮して $15 \mathrm{~mA}$ とした。

3.2.2 アルゴン流量の影響シースガス流量を(1〜 4) $1 / \mathrm{min}$ ，キャリヤーガス流量を $0 \sim 15 \mathrm{ml} / \mathrm{min}$ の範囲 でそれぞれ変化させ, 吸光度を測定し, アルゴン流量の 影響を検討した。

シースガス流量の変化は吸光度にほとんど影響を及ぼ さなかった. キャリヤーガスは, 流量の増加に伴って吸 光度を低下させたので流さないこととした.

3.2.3 乾燥, 灰化及び原子化条件の影響 乾燥, 灰 化及び原子化の各段階における温度を変化させて吸光度 を測定し，温度条件の影響を検討した. 結果を Fig. 1 に示す.

乾燥, 灰化及び原子化の各段階における温度を, それ ぞれ高感度を得られる $120^{\circ} \mathrm{C}, 400^{\circ} \mathrm{C}$ 及び $2540{ }^{\circ} \mathrm{C}$ と した.

乾燥及び灰化の時間は，いずれも $(20 \sim 60)$ 秒の検討 範囲内で吸光度に影響を与えなかったので 30 秒とし た. 原子化時間は，5秒以上で一定の吸光度が得られた ので 7.5 秒とした.

3.2.4 スリット幅, 応答速度及びスケール拡大の影

泪 スリット幅, 応答速度及びスケール拡大を変化さ せ，ピーク高さとベースラインのノイズ幅を測定し，検

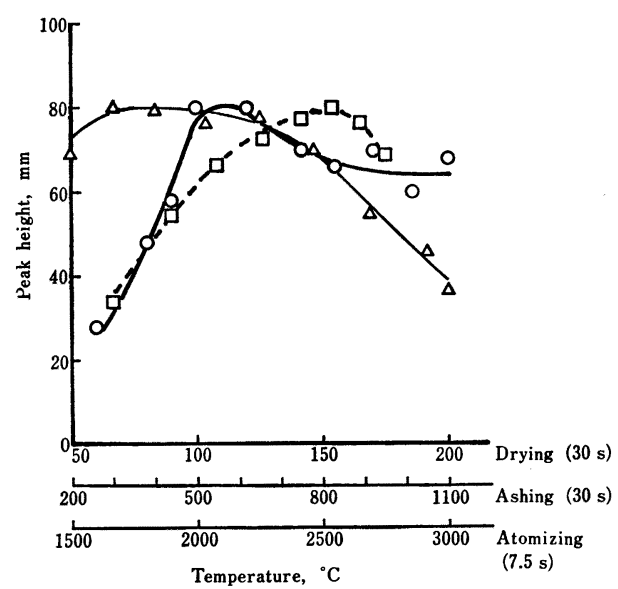

Fig. 1 Effect of heating programs $\mathrm{O}:$ Drying; $\triangle$ Ashing; $\square:$ Atomizing; $\mathrm{Sb}: 0.04$
$\mathrm{ug} / \mathrm{ml}$

出限界を, ベースラインのばらつき（標準偏差）の 3 倍 のピーク高さを与える濃度と定義し算出して比較検討し た。

検出限界は，スリット幅に大きく影響されたが，装置 の表示で, スリット幅 3 , 応答速度 3 , スヶール拡大 5 で $0.002 \mu \mathrm{g} / \mathrm{ml}(20 \mu \mathrm{l}$ 注入) であった. なお, アンチ モン濃度 $0.04 \mu \mathrm{g} / \mathrm{ml}$ での変動係数は $2.5 \% \quad(n=10)$ であった。

3.2.5 検量線 アンチモン標準液 (A) は, 塩化ア ンチモン(III) の塩酸酸性溶液である.塩化アンチモン (III) は沸点 $\left(223^{\circ} \mathrm{C}\right)$ が比較的低いので原子化以前の 段階で蒸発損失し低い吸光度を与えるおそれがあったの で, 蒸発損失の扢それのないアンチモン標準液 (B) に ついても検量線を作成し比較した. 結果を Fig. 2 に示 †.

アンチモン標準液（A） と（B）の検量線は良く一致 し, かつ良好な直線性を示して抢り, アンチモンの損失 は認められなかった。

3.2.6 共存酸の影響 塩酸, 硝酸, 硫酸, 過塩素酸 あるいはリン酸の各量をそれぞれ単独に加え吸光度を測 定した.結果を Fig. 3 に示す.

塩酸の影響はほとんど認められなかった。その他の酸 については, 濃度の増加により吸光度が低下した. 硫酸 は原子化部をミストで污染する傾向が強く, 好ましくな かった。リン酸は濃度が高くなるとから試験值が急激に 上昇した。

3.2.7 クロムの影響 金属クロム中のアンチモンを 共存成分からの分離などの前処理を行うことなく定量す 


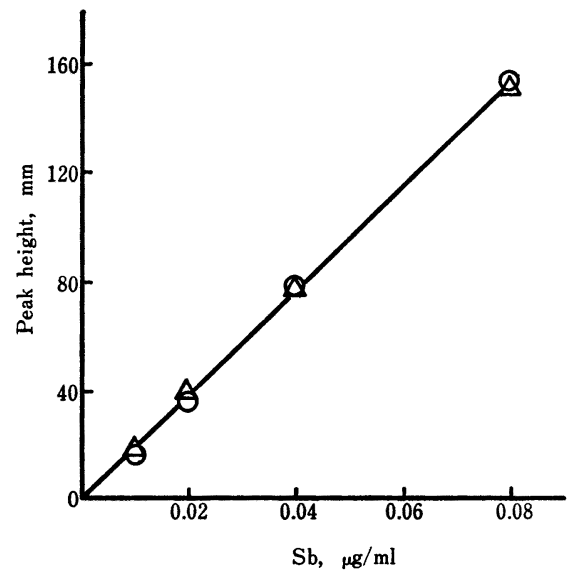

Fig. 2 Comparison of calibration curves of antimony standard solution (A) and (B) for the concentration of less than $0.1 \mu \mathrm{g} / \mathrm{ml}$ $\bigcirc$ Antimony standard solution (A), $\triangle$ Antimony standard solution (B)

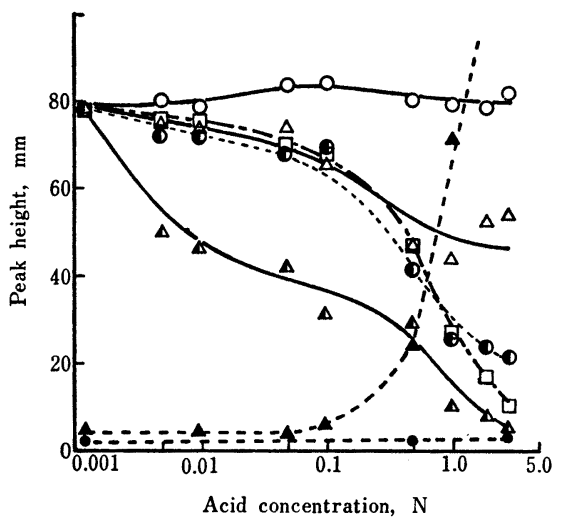

Fig. 3 Effect of various acids $\mathrm{O}: \mathrm{HCl}, \triangle: \mathrm{HNO}_{3}, \square: \mathrm{H}_{2} \mathrm{SO}_{4}, \bigcirc: \mathrm{HClO}_{4}, \triangle:$
$\mathrm{H}_{3} \mathrm{PO}_{4}, \triangle:$ Blank of $\mathrm{HCl}_{4} \mathrm{HNO}_{3}, \mathrm{H}_{2} \mathrm{SO}_{4}$, and
$\mathrm{HClO}_{4}, \triangle$ : Blank of $\mathrm{H}_{3} \mathrm{PO}_{4} ; \mathrm{Sb}: 0.04 \mu \mathrm{g} / \mathrm{ml}$

る場合，検液中には大量のクロムが共存することにな る.

塩化物あるいは硝酸塩の形でクロムの各量をそれぞれ 単独に加えて吸光度を測定しクロムの影響を検討した。 結果を Fig. 4 亿示す.

塩化物では $5000 \mu \mathrm{g} / \mathrm{ml}$ までは，途中で若干の增加を 認めたがほぼ一定の吸光度を示し，それ以上の濃度で急 激に低下した．硝酸塩では $1000 \mu \mathrm{g} / \mathrm{ml}$ までは，ほぼ一 定の吸光度を示した。

なお，塩化物，硝酸塩ともに $5000 \mu \mathrm{g} / \mathrm{ml}$ 以上の濃度

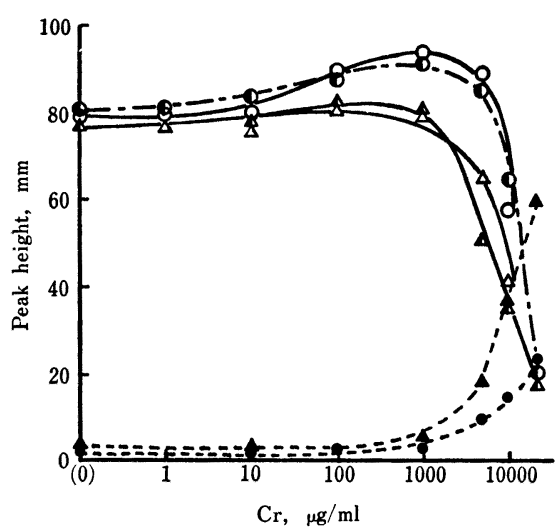

Fig. 4 Effect of chromium
$\bigcirc$ Chloride, $\triangle$ Nitride : Condition in Table 1 (1)
(1) Chloride, $\triangle$ Nitride : Condition in Table 1 (2);
- Blank of chloride, $\Delta$ Blank of nitride : Condition in Table 1 (2); $\mathrm{Sb}: 0.04 \mu \mathrm{g} / \mathrm{ml}$

では，乾燥あるいは灰化の過程で突沸，原子化の過程で バックグラウンドの吸收過大の 現象が現れるようにな り,このような場合には測定を不能とした。

$$
4 \text { 金属ク口ムの分析 }
$$

\section{1 定量操作}

試料 $0.25 \mathrm{~g}$ を三角フラスコに量り取り, 塩酸 $(1+1)$ $3.0 \mathrm{ml}$ 及び硝酸 $(1+1) 0.2 \mathrm{ml}$ を加え, 還流冷却器を 取り付けて常温で分解した．放冷後 $50 \mathrm{ml}$ メスフラス コに移し，水で標線までうすめて検液とした。

検液 $20 \mu \mathrm{l}$ をマイクロピペットで黒鉛管に注入し Table 1 (2) 飞示す測定条件で吸光度を測定して, 同時 そアンチモン標準夜（A）を用いて作成した検量線から アンチモン量を算出した.

\section{2 結果と考察}

4.2.1 測定条件の再設定 金属クロムを分解して得 られる検液から，分離などの前処理を行らことなく直接 微量アンチモンを定量する場合, Table 1 （1）に示し た標準液での測定条件ではクロム濃度 $5000 \mu \mathrm{g} / \mathrm{ml}$ 以上 で突沸やバックグラウンドの吸収過大のため測定を不能 にすることがあった $(3 \cdot 2 \cdot 7)$ ので，この程度の濃度でも 測定可能な条件を見いだすため, 乾燥, 灰化時の温度, 時間及びモードの 再検討を行い，測定条件を再設定し た. 得られた結果を Table 1 (2) に示す.

本条件によれば， $10000 \mu \mathrm{g} / \mathrm{ml}$ 程度の濃度までは突沸 現象などは認められなかった。

4.2.2 クロムの影響 Table 1（2）の測定条件で, 
$3 \cdot 2 \cdot 7$ に相当する実験を行った. 結果を Fig. 4 に併せ て示したが，測定条件が変わっても両者のパターンは同 様であったので，検液中のクロム (塩化物) 濃度を 5000 $\mu \mathrm{g} / \mathrm{ml}$ とした.

\subsection{3 クロム共存下での共存成分の影響 検液中に}

は，金属クロム中に不純物として $0.1 \%$ 程度含まれる 鉄及び分解に用いた塩酸, 硝酸が共存するので, クロム $5000 \mu \mathrm{g} / \mathrm{ml}$ 共存下での鉄及び酸の影響を検討した。

鉄（塩化物）は $10 \mu \mathrm{g} / \mathrm{ml}$ の濃度までは影響がなく， $10 \mu \mathrm{g} / \mathrm{ml}$ 以上で吸光度を 低下させた。酸はクロムが共 存しない場合 (Fig. 3) と同様なパターンを示した.

4.2.4 実試料の分析 4.1 に従い実試料の分析を行 い, 同時に試料にアンチモン標準液（A）を加えて回収 量を求めた. 結果を Table 2 に示す.

Table 2 Analytical results of practical samples

\begin{tabular}{|c|c|c|c|}
\hline Sample & $\begin{array}{l}\text { Sb added } \\
(\mu \mathrm{g})\end{array}$ & $\begin{array}{l}\text { Sb found } \\
(\mu \mathrm{g})\end{array}$ & $\begin{array}{c}\mathrm{Sb} \\
(\mathrm{ppm})\end{array}$ \\
\hline \multicolumn{4}{|c|}{ Electrolytic chromium metal } \\
\hline I & $\begin{array}{l}0 \\
1.0 \\
2.0\end{array}$ & $\begin{array}{r}<0.1 \\
1.0 \\
2.0\end{array}$ & $<0.4$ \\
\hline II & $\begin{array}{l}0 \\
1.0 \\
2.0\end{array}$ & $\begin{array}{r}<0.1 \\
1.0 \\
1.8\end{array}$ & $<0.4$ \\
\hline III & $\begin{array}{l}0 \\
1.0 \\
2.0\end{array}$ & $\begin{array}{r}<0.1 \\
1.0 \\
2.0\end{array}$ & $<0.4$ \\
\hline
\end{tabular}

実試料中のアンチモンはいずれも $0.4 \mathrm{ppm}$ 以下で, ジイソプロピルエーテル抽出ーローダミン B吸光光度法 によって得られた值（いずれも $0.2 \mathrm{ppm}$ 以下）と一致 し添加回収実験の結果も満足できた。

これらの結果から, 本法は電解金属クロム中の数 $\mathrm{ppm}$ 以下の微量アンチモンの迅速分析法として有効であるこ とが分かった。

\section{交献}

1) R. Kiessling : Met Sci., May, 161 (1980).

2) D. R. Wood : Metallurgia, 67, 109 (1963).

3) W. H. Evans, F. J. Jackson, D. Dellar : Analyst (London), 104, 16 (1979).

4) W. French : Talanta, 21, 565 (1974).

5) M. Yanagisawa, T. Takeuchi, M. Suzuki : Anal. Chim. Acta, 64, 381 (1973).

6) C. Y. Chan, P. N. Vijan : Anal. Chim. Acta, 101, 33 (1979).

7) 久保田敏夫, 植田俊夫 : 分化, 27, 692 (1978).

8) W. B. Robbins, J. A. Caurse : Analyst (Lon- don), 104, 35 (1979).

9) 池田昌彦, 西部次郎, 中原武利：分化，30,545 (1981).

10) R. M. Hamner, D. L. Lechak, P. Greenberg : At. Absorp. Newsl., 15 ( 5 ), 122 (1976).

11) British Steel Corp. : NTIS, PBREP, PB-256053, 1, 99 (1976).

12) G. C. Kunselum, E. A. Huff : At. Absorp. Newsl., 15 ( 2 ), 29 (1976).

药

Determination of antimony in electrolytic chromium metal by graphite furnace Zeeman atomic absorption spectrometry. Takashi Hôjyo and Shinkô Nagumo (Tokyo Research Laboratory, Toyo soda Manufacturing Co., Ltd., 2743-1, Hayakawa, Ayase-shi, Kanagawa, 252)

A rapid and high sensitive analytical method by a Zeeman atomic absorption spectrometry was developed for determination of antimony less than a few ppm in electrolytic chromium metal without preseparation. Preliminary studies using antimony standard solution less than $0.1 \mu \mathrm{g} / \mathrm{ml}$ showed that (1) a limit of detection was $0.002 \mu \mathrm{g} / \mathrm{ml}$ and a coefficient of variation was 2.5 $\%(n=10)$ at the concentration of $0.04 \mu \mathrm{g} / \mathrm{ml}$ as antimony, under the optimum instrumental operating condition, and (2) significant suppression effects were observed for nitric acid, sulfuric acid, perchloric acid, phosphoric acid, and chromium when they were in high concentration but iron showed the suppression effect in comparatively low concentration. When chromium presented more than $5000 \mu \mathrm{g} / \mathrm{ml}$ in the solution, a modification of drying and ashing conditions were required, because of appearance of bumping and/or of too large background absorbance. Outline of proposed method is as follows; $0.25 \mathrm{~g}$ of chromium metal are dissolved in $3 \mathrm{ml}$ of $(1+1) \mathrm{HCl}$ and $0.2 \mathrm{ml}$ of $(1+1)$ $\mathrm{HNO}_{3}$ using a Erlenmeyer flask with a reflux condenser. After dissolving the solution is diluted to $50 \mathrm{ml}$ with water. Twenty microliter of the solution is pipetted into a graphite furnace. Atomization program of the furnace is as follows; Drying: at $200^{\circ} \mathrm{C}$ ramp mode, Ashing: at $560^{\circ} \mathrm{C}$ for $120 \mathrm{~s}$, Atomizing: at $2540^{\circ} \mathrm{C}$ for $7.5 \mathrm{~s}$. The content of antimony is obtained from the absorbance at $217.5 \mathrm{~nm}$, using the calibration curve. The detection limit of this proposed method was 0.4 ppm. As results of application of this proposed method to some products, they were in good agreement with those obtained by means of a spectrophotometric method (Rhodamine B method).

(Received August 26, 1983)

\section{Keyword phrases}

determination of antimony in electrolytic chromium metal; determination of antimony by graphite furnace Zeeman atomic absorption spectrometry. 